\title{
Silencing of the IKK $\varepsilon$ gene by siRNA inhibits invasiveness and growth of breast cancer cells
}

Bin Qin, Kun Cheng*

\begin{abstract}
Introduction: $\mid \kappa B$ kinase $\varepsilon(I K K \varepsilon)$ is a member of the IKK family that plays an important role in the activation of NF$\kappa \mathrm{B}$. Overexpressed in more than $30 \%$ of breast cancers, IKK $\varepsilon$ has been recently identified as a potential breast cancer oncogene. The purpose of the present study is to examine the therapeutic potential of IKKE siRNA on human breast cancer cells.
\end{abstract}

Methods: Eight siRNAs targeting different regions of the IKKE mRNA were designed, and the silencing effect was screened by quantitative real-time RT-PCR. The biological effects of synthetic siRNAs on human breast cancer cells were investigated by examining the cell proliferation, migration, invasion, focus formation, anchorage-independent growth (via soft agar assay), cell cycle arrest, apoptosis (via annexing binding), NF- $\kappa$ B basal level, and NF- $\kappa$ B-related gene expressions upon the IKKE silencing.

Results: Silencing of IKKE in human breast cancer cells resulted in a decrease of focus formation potential and clonogenicity as well as in vitro cell migration/invasion capabilities. Moreover, knockdown of IKKE suppressed cell proliferation. Cell cycle assay showed that the anti-proliferation effect of IKKE siRNA was mediated by arresting cells in the $G_{0} / G_{1}$ phase, which was caused by downregulation of cyclin $D_{1}$. Furthermore, we demonstrated that silencing of IKKE inhibited the NF- $\kappa$ B basal activity as well as the Bcl-2 expression. Significant apoptosis was not observed in breast cancer cells upon the silencing of IKKE. The present study provided the first evidence that silencing IKKE using synthetic siRNA can inhibit the invasiveness properties and proliferation of breast cancer cells.

Conclusions: Our results suggested that silencing IKKe using synthetic siRNA may offer a novel therapeutic strategy for breast cancer.

\section{Introduction}

$\mathrm{I} \kappa \mathrm{B}$ kinase $\varepsilon$ (IKK $\varepsilon$, also named IKKi/IKBKE) is a member of the IKK family, which contains five distinct but closely related members: IKK $\alpha, \mathrm{IKK} \beta$, IKK $\gamma$, TBK-1 and IKK $\varepsilon[1,2]$. IKK is an important mediator of the activation of NF- $\kappa \mathrm{B}$, which is a heterodimeric transcription factor playing essential roles in inflammation and cancer pathogenesis. The NF- $\kappa \mathrm{B}$ family is composed of Rel A, Rel B, c-Rel, p50/p105 and p52/p100. Inhibitors of kappa $\mathrm{B}(\mathrm{I} \kappa \mathrm{Bs})$ bind to the homodimers or heterodimers of NF- $\kappa \mathrm{B}$ proteins and cause their cytoplasmic retention in an inactivated form. Upon stimulation, $\mathrm{I} \kappa \mathrm{Bs}$ are phosphorylated by IKK complexes - which leads to the ubiquitination and proteasomal degradation of $\mathrm{I} \kappa \mathrm{Bs}$. NF- $\kappa \mathrm{B}$ is then released and translocated into the nucleus to

\footnotetext{
* Correspondence: chengkun@umkc.edu

Division of Pharmaceutical Sciences, School of Pharmacy, University of Missouri-Kansas City, 2464 Charlotte Street, Kansas City, MO 64108, USA
}

regulate the expression of target genes involved in immune and inflammatory responses [3,4]. Discovered in 2000 , IKK $\varepsilon$ shows a $33 \%$ and $31 \%$ sequence identity with IKK $\alpha$ and IKK $\beta$, respectively, in the $\mathrm{N}$-terminal kinase domain, but has distinct function in the activation of NF- $\kappa$ B pathway [2,5]. Overexpression of IKK $\varepsilon$ is strongly correlated with the nuclear localization of c-Rel in breast cancer specimens, indicating that a substantial fraction of NF- $\kappa \mathrm{B}$ activation is induced by aberrant IKK $\varepsilon$ in breast cancer cells [6]. The relationship between $\mathrm{IKK} \varepsilon$ and NF- $\kappa \mathrm{B}$, however, is not fully understood $[4,7]$.

IKK $\varepsilon$ is primarily involved in signaling of inflammatory and immune processes $[8,9]$. Peant and colleagues reported that overexpression of IKK $\varepsilon$ in hormone-sensitive LNCaP and 22Rv1 prostate tumor cells induced secretion of numerous inflammatory cytokines, such as IL-8 and IL-6. However, the IKKe-dependent IL-8 and IL- 6 overexpressions are not mediated by the activation 
of NF- $\kappa \mathrm{B}$ pathway. Instead, the authors speculated that high IKKe expression leads to nuclear translocation of itself to activate these inflammatory cytokine genes [10]. Recently, the role of IKK $\varepsilon$ in cancer has been studied by several groups. Sonenshein and colleagues observed for the first time a higher level of IKKE in breast cancer cell lines and specimens, whereas little IKK $\varepsilon$ expression was detected in normal breast epithelial cells [11]. Furthermore, Boehm and colleagues indentified IKKE as a new potential oncogene in breast cancer cell lines and patient-derived tumors using three complementary genetic approaches. Overexpression of IKK $\varepsilon$ was observed in over $30 \%$ of breast cancer cell lines and carcinomas $[4,6,7]$. On the other hand, inhibition of IKK $\varepsilon$ in breast cancer cells with overexpressed IKKe induced cell death [6]. All these up-to-date data strongly support the role of IKKE in tumorigenesis, and subsequently blocking the IKK $\varepsilon$ expression would be a rational strategy to treat breast cancer.

Among various strategies to inhibit the oncogene expression, RNA interference (RNAi) offers considerable promise for cancer therapy due to its ability to potently knockdown a specific gene. siRNA of 21 to 23 nucleotides in length silences a target gene by binding to its complementary mRNA and triggering its degradation $[12,13]$. In the present study, we intend to evaluate the effect of silencing IKK $\varepsilon$ on colonigenicity, invasive properties, proliferation, and apoptosis in breast cancer cells using synthetic siRNA.

\section{Materials and methods Reagents}

Lipofectamine-2000 and TRIzol reagent were purchased from Invitrogen Corp. (Carlsbad, CA, USA), Cell culture products were obtained from Atlanta Biologicals, Inc. (Lawrenceville, GA, USA) and Mediatech, Inc. (Manassas, VA, USA). BSA was purchased from Sigma-Aldrich Corporation (St Louis, MO, USA). SYBR Green-1 dye universal master mix and Multiscript RT were purchased from Applied Biosystems, Inc. (Foster City, CA, USA). The $6.5 \mathrm{~mm}$ Transwell ${ }^{\circ}$ with $8.0 \mu \mathrm{m}$ Pore Polycarbonate Membrane Insert was purchased from Corning Incorporated (Lowell, MA, USA). BD Matrigel ${ }^{\mathrm{Tw}}$ and BD Pharmingen $^{\mathrm{nt}}$ Annexin V-FITC Apoptosis Detection Kit I was obtained from BD Biosciences (San Jose, CA, USA). The CellTiter-Glo ${ }^{\circ}$ Luminescent Cell Viability Assay Kit was purchased from Promega Corp. (Madison, WI, USA). The NF- $\kappa$ B-Met-Luc2 reporter vector was obtained from Clontech Laboratories, Inc. (Mountain View, CA, USA). 3-(4,5-Dimethylthiazol-2yl)-2,5-diphenyltetrazolium bromide (MTT) was purchased from Research Products International Corp. (Mt. Prospect, IL, USA). Cisplatin was obtained from Enzo Life Sciences, Inc. (Plymouth Meeting,
PA, USA). Doxorubicin hydrochloride was purchased from Thermo Fisher Scientific (Pittsburgh, PA, USA).

\section{Cell lines and culture conditions}

All cell lines (human breast cancer cell lines, SK-BR-3 and MCF-7) were purchased from the American Type Culture Collection, and were maintained in RPMI-1640 medium supplemented with $10 \%$ FBS, penicillin (100 unit $/ \mathrm{ml})$, and streptomycin $(100 \mu \mathrm{g} / \mathrm{ml})$. Both cell lines were cultured at $37^{\circ} \mathrm{C}$ in a humidified atmosphere containing $5 \%$ carbon dioxide. The culture medium was changed every other day and the cells were passaged when they reached 80 to $90 \%$ confluency.

\section{siRNA design and synthesis}

siRNAs targeting IKKe [GenBank: NM_014002] were designed using BLOCK-iT ${ }^{\mathrm{mm}}$ RNAi Designer (Invitrogen), siRNA Target Finder (Ambion, Austin, TX, USA), siRNA Target Finder (GeneScript, Piscataway, NJ, USA) and siRNA target Designer (Promega). Eight siRNAs targeting different regions of IKK $\varepsilon$ mRNA were designed (Table 1) and were purchased from Ambion and Invitrogen. These synthetic siRNAs are of 19 nucleotides with two thymidine deoxynucleotide (T) 3' overhangs. All designed siRNA sequences were blasted against the human genome database to eliminate cross-silence phenomenon with nontarget genes. Scrambled siRNA (Ambion) that does not target any gene was used as the negative control siRNA.

\section{Transfection of siRNA}

Cells were transfected with siRNA and Lipofectamine2000 according to the manufacturer's instructions. Briefly, cells were seeded in a 24-well-plate at a density of $0.5 \times 10^{5}$ cells/well with antibiotics-free medium 12 hours before the transfection. One and a half microliters of the siRNA $(20 \mu \mathrm{M})$ were mixed with $1 \mu \mathrm{l}$ Lipofectamine-2000 in $50 \mu \mathrm{l}$ serum-free RPMI-1640 medium and were incubated at room temperature for 25 minutes to form a complex. After washing cells with PBS, the $50 \mu \mathrm{l}$

Table $\mathbf{1}$ Sense strand sequence of IKKe siRNA [GenBank:
NM_014002]
\begin{tabular}{lll}
\hline Number & Starting site & Sequence \\
\hline siR-1 & 482 & 5'-GGUCUUCAACACUACCAGCtt-3' \\
siR-2 & 2538 & 5'-GGCAUCCUGAAGCAUUAGAtt-3' \\
siR-3 & 551 & 5'-GCUGAACCACCAGAACAUCtt-3' \\
siR-4 & 533 & 5'-GUUUGAGGUCCUGCGGAAGtt-3' \\
siR-5 & 820 & 5'-GCAUCUACAAGCUGACAGAtt-3' \\
siR-6 & 1960 & 5'-GGGAUCAGGUACAUGAGGAtt-3' \\
siR-7 & 1968 & 5'-GUACAUGAGGACAGAAGCAtt-3' \\
siR-8 & 1978 & 5'-ACAGAAGCAUCCAGCAGAUtt-3' \\
\hline
\end{tabular}


transfection mixtures were added to each well with $450 \mu \mathrm{l}$ RPMI-1640 medium containing 10\% FBS at a final concentration of $50 \mathrm{nM}$ siRNA. Twenty-four hours after the transfection, the medium was replaced with fresh $500 \mu \mathrm{l}$ RPMI-1640 medium containing 10\% FBS. Forty-eight hours after the transfection, cells were collected for RNA and protein isolation.

\section{Real-time RT-PCR}

Total RNA was isolated from cells using TRIzol reagent according to the manufacturer's protocol. Total RNA (200 ng) was converted to cDNA using random hexamer primer and MultiScribe Reverse Transcriptase Reagent. One hundred nanograms of cDNA were amplified by real-time PCR using SYBR Green-1 dye universal Master mix on an ABI Prism 5700 Sequence Detection System (Applied Biosystems). To confirm the PCR specificity, PCR products were subjected to a melting-curve analysis. The comparative threshold method was used to calculate the relative amount of mRNA of treated sample in comparison with control samples $[14,15]$. The primers used for the study included: IKKE, 5'-ACTCTGGAAGTGGCAA GGACAT-3' (forward) and 5'-TACCTGATCCCGGCTCTTCACCA-3' (reverse); IKK $\alpha, 5^{\prime}$-TCT GGAACAGCGTGCCATTGATCT-3' (forward) and 5'ATTACTGAGGGCCACTTCCACCTT-3' (reverse); IKK $\beta$, 5'-ACTGGAGCAGCAGAAGTACACAGT-3' (forward) and 5'-ATCAG CATCAGTTGCAGCCACTTC-3' (reverse); TBK1, 5'-AGGATTGCCTGATCCAGCCAAGAT-3' (forward) and 5'-CCACTGGACGAAGGAAGCTTATGC-3' (reverse); and Bcl-2, 5'-AGGCAT GTTGACTTCACTTGTGGC-3' (forward) and 5'GCATGCGGCCTCTGTTTGATTTCT-3' (reverse). We used 18s ribosomal RNA as an internal control, and the primers were 5'-GTCTGTGATGCCCTTAGATG-3' (forward primer), and 5'-AGCTTATGACCCGCACTT AC3 ' (reverse primer).

\section{Western blotting}

The cultured cells were washed twice with ice-cold PBS and lysed on ice in RIPA lysis buffer containing freshly added protease and phosphatase inhibitor cocktails. After 5 minutes of incubation, the cell lysate was collected by centrifugation at $4^{\circ} \mathrm{C}$ for 10 minutes at 12,000 $\mathrm{rpm}$. The amount of total protein was determined using a BCA protein assay kit (Pierce, Rockford, IL, USA). An equal amount of total protein $(20 \mu \mathrm{g})$ was loaded and separated by SDS-PAGE. The protein was transferred to a nitrocellulose membrane, blocked and probed with appropriate antibodies. The protein was then visualized using horseradish peroxidase-conjugated secondary antibodies and the FluorChem FC2 imaging system (Alpha Innotech, San Leandro, CA, USA). Anti-IKKe/IKKi antibody (Sigma-Aldrich), anti- $\beta$-Actin antibody (Rockland,
Gilbertsville, PA, USA), anti-Bcl2 antibody (Abcam, Cambridge, MA, USA), anti-cyclin $\mathrm{D}_{1}$ (Abcam) and horseradish peroxidase-conjugated secondary antibody (Invitrogen) were used in the western blotting assay.

\section{Focus formation assay}

Forty-eight hours after the transfection, $5 \times 10^{3}$ MCF-7 cells/well or $7.5 \times 10^{3} \mathrm{SK}-\mathrm{BR}-3$ cells/well were seeded in six-well plates. The medium was changed every 2 days. Cells cultured for 9 days were washed twice with icecold medium, fixed by ice-cold methanol, and stained with $0.2 \%$ crystal violet. Images of the colonies were obtained using a digital camera.

\section{Soft agar assay}

Colony formation ability was examined by anchorageindependent soft agar assay on MCF-7 cells. Briefly, $1.5 \mathrm{ml}$ FBS supplemented medium containing 0.5\% agarose were added in $35-\mathrm{mm}$ cell culture dishes and allowed to solidify (base agar). Next, $1 \times 10^{4}$ siRNAs transfected MCF-7 cells were mixed with $1.5 \mathrm{ml} \mathrm{FBS-}$ supplemented medium containing $0.35 \%$ agarose and added to the top of base agar. The cells were then cultured for 14 days at $37^{\circ} \mathrm{C}$ under $5 \%$ carbon dioxide. The dishes were stained with $0.005 \%$ crystal violet, and the colonies were examined with microscope and digital camera.

\section{Wound healing assay}

SK-BR-3 cells seeded in 12-well plates $\left(2 \times 10^{5}\right.$ cells/well $)$ were transfected with $50 \mathrm{nM}$ siRNA as described above. Once the cells reached $90 \%$ confluency, a wound area was carefully created by scraping the cell monolayer with a sterile $10 \mu \mathrm{l}$ pipette tip. The cells were then washed once with Dulbecco's PBS to remove detached cells. Subsequently, the cells were incubated at $37^{\circ} \mathrm{C}$ in $5 \%$ carbon dioxide. The width of the wound area was monitored with an inverted microscope at various time points. The normalized wound area (wound $\mathrm{area}_{48} \mathrm{hours}_{\mathrm{w}} / \mathrm{wound}_{\mathrm{area}}$ hours) was calculated using the software TScratch [16].

\section{Migration assay and invasion assay}

We evaluated the effect of IKK $\varepsilon$ siRNA on invasiveness properties of breast cancer cells using transwell migration and invasion assays. Forty-eight hours after the transfection, SK-BR-3 cells or MCF-7 cells were trypsinized and resuspended in FBS-free RPMI-1640 medium. For the migration assay, a total of $1 \times 10^{5}$ cells were plated in the top chamber of the transwell with a noncoated polycarbonate membrane $(6.5 \mathrm{~mm}$ diameter insert, $8.0 \mu \mathrm{m}$ pore size; Corning Incorporated). For the invasion assay, $1 \times 10^{5}$ cells were plated in the top chamber of the transwell with a matrigel-coated polycarbonate membrane. RPMI-1640 medium with 10\% FBS 
was added to the lower chamber as a chemoattractant. After incubation for 48 hours (migration assay) or 60 hours (invasion assay), cells on the lower surface of the membrane were fixed with $10 \%$ formalin and stained with $0.2 \%$ crystal violet. Cells that did not migrate through the pores were mechanically removed by a cotton swab [17]. The images of migrated cells were acquired by an inverted microscope with a magnification of $200 \times$. The number of migrated or invaded cells was counted from five or six randomly selected fields in a blind way.

\section{Cell proliferation assay}

The effect of siRNA on cell proliferation was measured using the CellTiter-Glo ${ }^{\circ}$ Luminescent Cell Viability Assay Kit (Promega) according to the manufacturer's protocol. Briefly, SK-BR-3 cells (5,000 cells/well) or MCF-7 cells (2,500 cells/well) seeded in 96-well plates were transfected with $50 \mathrm{nM}$ siRNA as described above. Seventytwo hours and 120 hours after the transfection, $100 \mu \mathrm{l}$ CellTiter-Glo ${ }^{\circ}$ reagent was added to each well that contained $100 \mu \mathrm{l}$ cell culture medium. Cells were then lysed by shaking in an orbital shaker for 2 minutes, followed by incubation at room temperature for 10 minutes to stabilize the luminescent signal. The luminescent intensity was measured using a Beckman DTX 880 multimode Detector (Beckman coulter, Inc., Brea, CA, USA).

\section{NF- $\kappa \mathrm{B}$ transcriptional activity assay}

The transcriptional activity of NF- $\kappa \mathrm{B}$ was examined using a Ready-To-Glow ${ }^{\mathrm{Tm}}$ secreted luciferase reporter system, NF- $\kappa$ B-Met-Luc2, which contains the NF- $\kappa \mathrm{B}$ promoter element upstream of the luciferase gene. The expression of luciferase was used to monitor the activity of NF- $\kappa$ B. Fifty thousand SK-BR-3 cells or MCF-7 cells were seeded in 24-well plates and transfected with siRNAs. Twenty-four hours after siRNA transfection, the cells were co-transfected with NF- $\kappa$ B-Met-Luc2 reporter vector and $\beta$-galactosidase reporter vector (used as an internal control). The culture medium was collected 24 hours post-transfection to measure the luciferase activity. The cells were lysed with reporter lysis buffer and the $\beta$-galactosidase activities of whole cell lysate were measured. The relative luciferase activity was calculated by normalizing results with the $\beta$-galactosidase expression.

\section{Cell cycle assay and apoptosis assay}

Forty-eight hours after the siRNA transfection, the cells were collected and fixed with ice-cold $70 \%$ ethanol. Before staining, the cells were washed with Dulbecco's PBS and incubated with propidium iodide/RNase staining buffer for 30 minutes at room temperature. Cell cycle analysis was carried out with a FACSCalibur Flow cytometer (BD Biosciences). To analyze apoptosis, cells were collected 72 hours post-transfection, and then stained with Annexin V-FITC and propidium iodide using the Annexin V-FITC Apoptosis Detection Kit I. The percentage of apoptotic cells was quantified by a FACSCalibur Flow cytometer. Paclitaxel (100 nM, 24-hour incubation) was used in the apoptosis assay as an apoptosis inducer to validate the measurements.

\section{Combinational treatment of cells with siRNA and chemotherapy agents}

Cells $(10,000$ cells/well) were seeded in a 96-well plate and transfected with siRNA as described above. Twentyfour hours after the transfection, the cells were incubated with medium supplemented with serial concentrations of cisplatin and doxorubicin for another 24 hours. Untransfected cells treated with different concentration of cisplatin or doxorubicin are defined as medium control group. Cell viability was then determined by MTT assay. MTT in PBS was added into cells at a final concentration of $0.5 \mathrm{mg} / \mathrm{ml}$. After 1 hour of incubation at $37^{\circ} \mathrm{C}$, the medium was aspirated and $100 \mu \mathrm{l}$ dimethylsulfoxide was added to dissolve the cells and the absorbance was measured at $570 \mathrm{~nm}$.

\section{Statistical analysis}

Data were expressed as the mean \pm standard deviation. Difference between any two groups was determined by analysis of variance. $P<0.05$ was considered statistically significant.

\section{Results}

\section{Silencing of IKK $\varepsilon$ gene by predesigned siRNAs}

To silence IKKE expression, we designed up to eight siRNAs (Table 1) targeting different mRNA regions of IKKE. Silencing effects of these predesigned IKKE siRNAs were examined in SK-BR-3 cells at a concentration of $50 \mathrm{nM}$ after complexation with Lipofectamine-2000. A scrambled siRNA that does not target any gene was used as the negative control. All eight siRNAs showed a significant silencing effect $(P<0.05)$ and knocked down 55.2 to $77.9 \%$ of IKKe mRNA in comparison with scrambled siRNA (Figure 1a). Among them, siR-1 and siR-8 showed the greatest suppression of IKK $\varepsilon$ and therefore these two siRNAs were selected for subsequent biological studies. Considering the fact that siRNA transfection efficiency may vary in different cell lines, we also examined the silencing effects of siR-1 and siR- 8 in MCF-7 cells. Approximately $61.3 \%$ and $59.0 \%$ of IKK $\varepsilon$ mRNA were silenced in MCF-7 cells after treatment with siR-1 and siR-8 (Figure 1b), respectively. The silencing effect of IKK $\varepsilon$ expression at the protein level was also confirmed with western blot. As shown in Figure 1c, both siR-1 and siR-8 significantly 



Figure 1 Silencing effect of predesigned IKK $\varepsilon$ siRNAs in SK-BR-3 and MCF-7 cells. (a) SK-BR-3 cells were transfected with eight predesigned IKKe siRNAs (siR-1 to siR-8) and negative control siRNA (NC) at a concentration of $50 \mathrm{nM}$. Cells were harvested 48 hours after the transfection, and the silencing effect at the IKKE mRNA level was determined using real-time RT-PCR. (b) MCF-7 cells were transfected with selected siR-1, siR8 , and NC. The Silencing effect at the IKKe mRNA level was measured using real-time RT-PCR. The silencing effect of IKKE siRNA at the protein level was determined using western blot in (c) SK-BR-3 cells and (d) MCF-7 cells. The effect of IKKe suppression on IKK $\alpha$, IKK $\beta$ and TBK1was examined in (e) SK-BR-3 cells and (f) MCF-7 cells.

inhibited the IKKe protein expression in SK-BR-3 cells and MCF-7 cells, which is consistent with the silencing effect at the mRNA level.

To study whether IKK $\varepsilon$ silencing upregulates other IKK kinases, we assayed the mRNA expression of IKK $\alpha$, IKK $\beta$ and TBK1 after silencing IKK $\varepsilon$ in MCF-7 cells and SK-BR-3 cells (Figure 2e, f). In both cell lines, IKKe suppression did not significantly influence the expressions of IKK $\alpha, \operatorname{IKK} \beta$ and TBK1 $(P>0.05)$.

\section{Silencing of IKK $\varepsilon$ inhibits focus formation of breast cancer cells}

First, we used a focus formation assay to test whether silencing IKK $\varepsilon$ in breast cancer cells affects the clonogenic potential, which correlates with tumor formation in vivo [18]. Forty-eight hours after the transfection, a single-cell suspension was seeded into six-well plates and incubated for 9 days to allow focus formation. The cells' foci were fixed, stained with crystal violet, and counted. As Figure 2a shows, SK-BR-3 cells treated with IKK $\varepsilon$ siRNA exhibited smaller focus diameter as well as focus numbers compared with cells treated with the scrambled siRNA. Similar results were also observed in MCF-7 cells (Figure 2b). These data indicated that inhibition of IKKE significantly decreases the cells' focus formation potential, which correlates with the formation of tumors in nude mice [19].

\section{Silencing IKKe inhibits anchorage-independent growth of} breast cancer cells

Anchorage-independent growth capability is one of the important characteristics of oncogenically transformed 


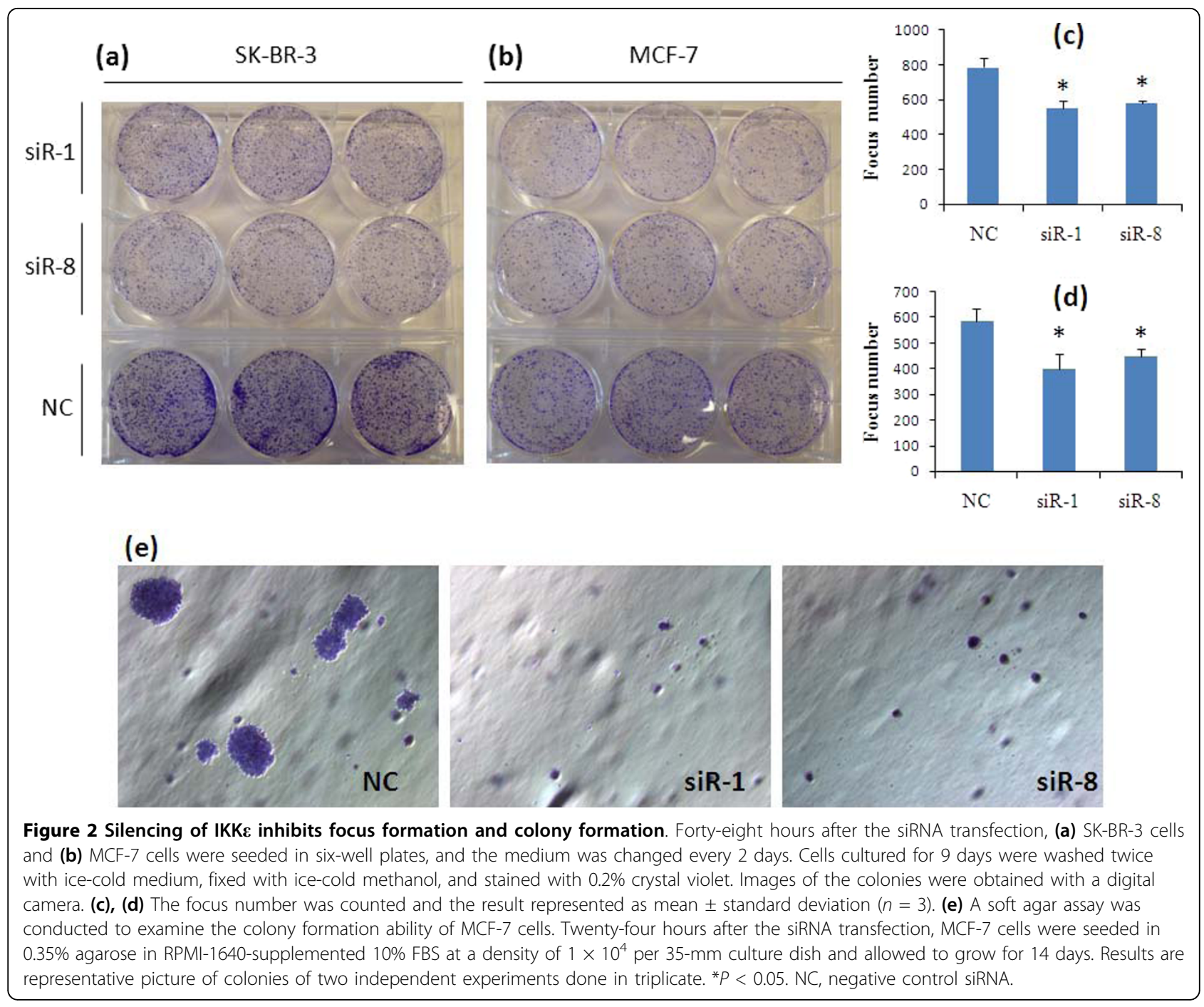

cells. In order to examine whether IKK $\varepsilon$ knockdown can influence the anchorage-independent growth potential, we performed a soft agar assay in MCF-7 cells. Twentyfour hours after the transfection, a single-cell suspension was seeded into $0.35 \%$ agarose supplemented with RPMI-1640 medium and 10\% FBS. The cells were cultured for another 14 days under normal cell culture conditions to allow colony formation. As shown in Figure 2e, silencing IKKe in MCF-7 cells dramatically inhibited the transformed phenotype. Individual colony size was much smaller in IKKe siRNA transfected cells compared with negative control siRNA-treated cells. This result indicated that silencing of IKK $\varepsilon$ in breast cancer cells suppress anchorage-independent growth capability.

\section{Silencing of IKK inhibits cell motility and invasion}

Decreased clonogenic potential is usually associated with the loss of invasion capabilities in tumor cells [18]. The cell motility of breast cancer cells was therefore tested using a classic wound healing assay in which the cell monolayer was scratched and cells migrating to the wound area were monitored at different time points. Compared with cells transfected with scrambled siRNA, the cells treated with siR- 1 and siR- 8 showed a wider wound area 48 hours after wound generation, and took a longer time to fill the wound area, indicating a defect in migration (Figure 3).

Since both cell migration and invasion are critical properties for the spreading of cancer cells and metastases, we further investigated the cell invasiveness using in vitro migration and invasion assays. Migration assay using uncoated Boyden chamber is a common method to examine the in vitro migration ability of tumor cells. Cells that migrated to the bottom of the transwell were fixed, stained and counted. Compared with the control group, IKKE siRNA transfected cells showed a significant decrease in the number of migrated cells in MCF-7 cells 


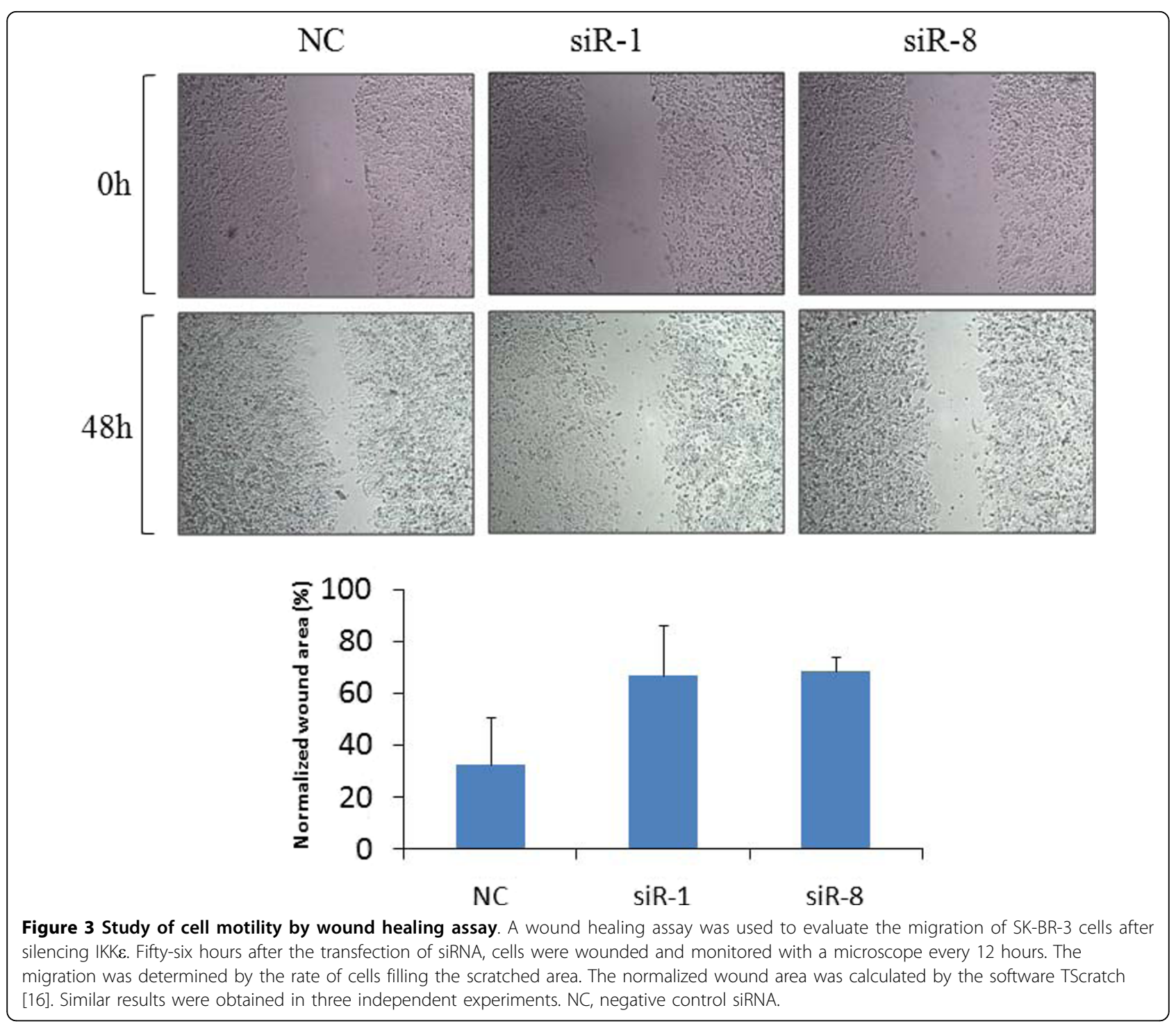

and SK-BR-3 cells (Figure 4a, b). Additionally, matrigelcoated transwell chambers were used to access the invasive capacities of breast cancer cells. Consistent with the finding in migration assay, cells treated with IKK $\varepsilon$ siRNA demonstrated significant reduction in cell invasion ability by 50 to $70 \%$ in SK-BR-3 cells and 30 to $73 \%$ in MCF-7 cells in comparison with scrambled siRNA-treated cells (Figure $4 \mathrm{a}, \mathrm{b}$ ). Taken together, these results indicate that silencing of IKK $\varepsilon$ decreases the invasive properties of breast cancer cells.

\section{Silencing of IKKE inhibits the proliferation of breast cancer cells}

Since oncogene is known to facilitate tumor cell growth, we next examined the proliferation of breast cancer cells after silencing of IKK $\varepsilon$ with siRNA. Cell growth was determined at 72 hours and 120 hours post-transfection.
Compared with cells transfected with the scrambled siRNA, cells treated with IKK $\varepsilon$ siRNAs demonstrated slower growth rate and lower viability (Figure 5). This observation is in accordance with the finding that a lentiviral shRNA targeting IKKe suppressed the proliferation and viability of MCF-7 cells [6]. These results suggested the pivotal role of IKK $\varepsilon$ in the proliferation and survival of breast cancer cells, and suppression of IKK $\varepsilon$ could lead to inhibition of cell proliferation. Moreover, the inhibition effect on cell proliferation is more significant at 120 hours rather than 72 hours posttransfection.

\section{Silencing of IKKE induces cell arrest in $G_{0} / G_{1}$ phase}

To identify the mechanism for this anti-proliferation effect, we investigated the cell cycle distribution of breast cancer cells after the silencing of IKK $\varepsilon$. As Figure 6 


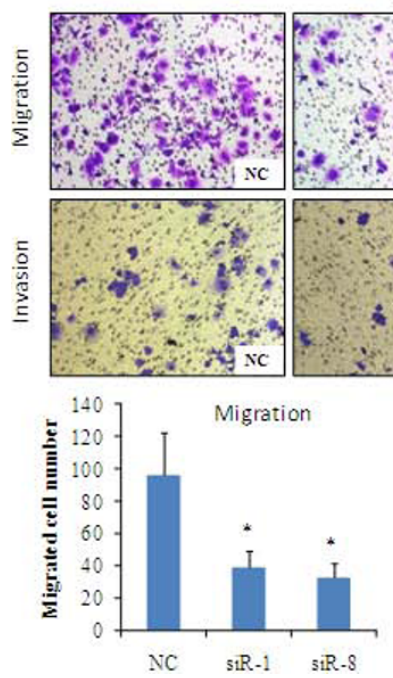

(a)
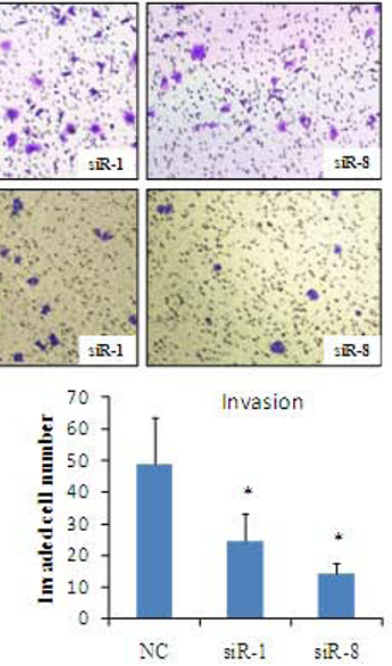

(b)
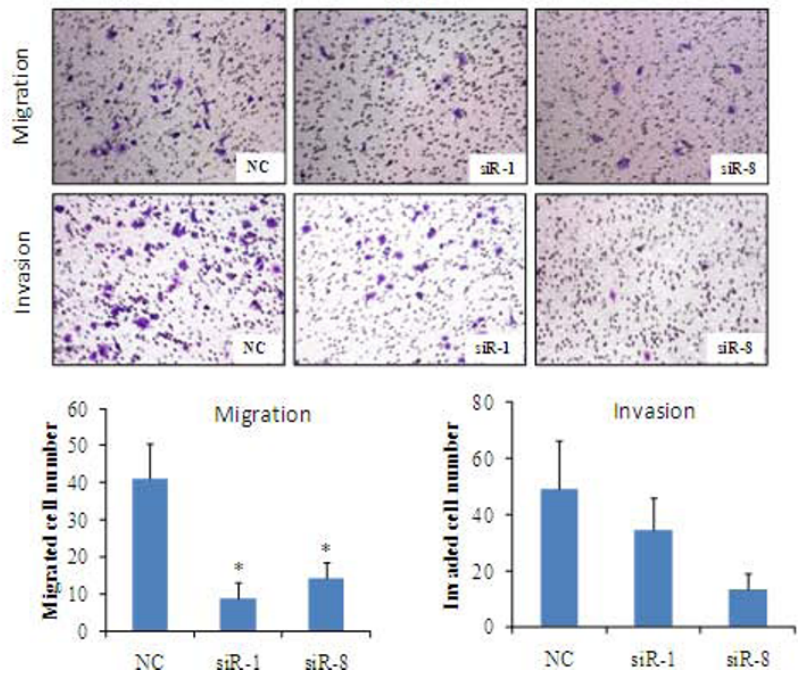

Figure 4 Silencing of IKK $\varepsilon$ expression inhibits migration and invasion abilities of SK-BR-3 cells and MCF-7 cells. Cell migration was determined using Boyden transwell chambers. Forty-eight hours after the transfection with siRNA, (a) SK-BR-3 cells and (b) MCF-7 cells were suspended in serum-free medium and seeded on 24-well transwell plates. RPMI-1640 with 10\% FBS was incubated in the lower chamber as the chemoattractant. Cells migrated though pores to the bottom surface of the transwell were fixed with $10 \%$ buffered formalin, stained with $0.2 \%$ crystal violet and counted. Six random microscopic fields were counted for each group. Cell invasion was assayed in transwell coated with Matrigel. Cells crossed the Matrigel-coated filter were fixed, stained and counted. Representative pictures of the bottom surface are shown. Six random microscopic fields were counted for each group. The results presented are an average of six random microscopic fields from three independent experiments. Significant reduction of migration and invasion was observed after silencing IKK $\varepsilon$ expression in SK-BR-3 cells and MCF-7 cells. ${ }^{*} P<0.05$. NC, negative control siRNA.

shows, cells transfected with IKKe siRNA induced a significant $\mathrm{G}_{0} / \mathrm{G}_{1}$ block in comparison with cells treated with scrambled siRNA. This was accompanied by a reduction of the proportion of $\mathrm{M}$-phase cells, while there was little difference in the $G_{2} / M$ distribution. The $G_{0} / G_{1}$ distribution of SK-BR-3 cells transfected with IKK $\varepsilon$ siR-1 and siR- 8 was $59.2 \%$ and $64.4 \%$, respectively, in comparison with $50.4 \%$ in cells treated with scrambled siRNA
(Figure 6a). In the same experiment, a similar result was observed in MCF-7 cells (Figure 6b). The percentages of cells in the $G_{0} / G_{1}$ phase were $61.1 \%$ and $61.8 \%$ for cells treated with siR-1 and siR-8, respectively. In comparison, only $54.3 \%$ of MCF-7 cells treated with scrambled siRNA were in the $G_{0} / G_{1}$ phase. The data revealed that IKK $\varepsilon$ siRNA inhibits cell proliferation via blocking cell cycle progression at the $G_{0} / G_{1}$ phase.
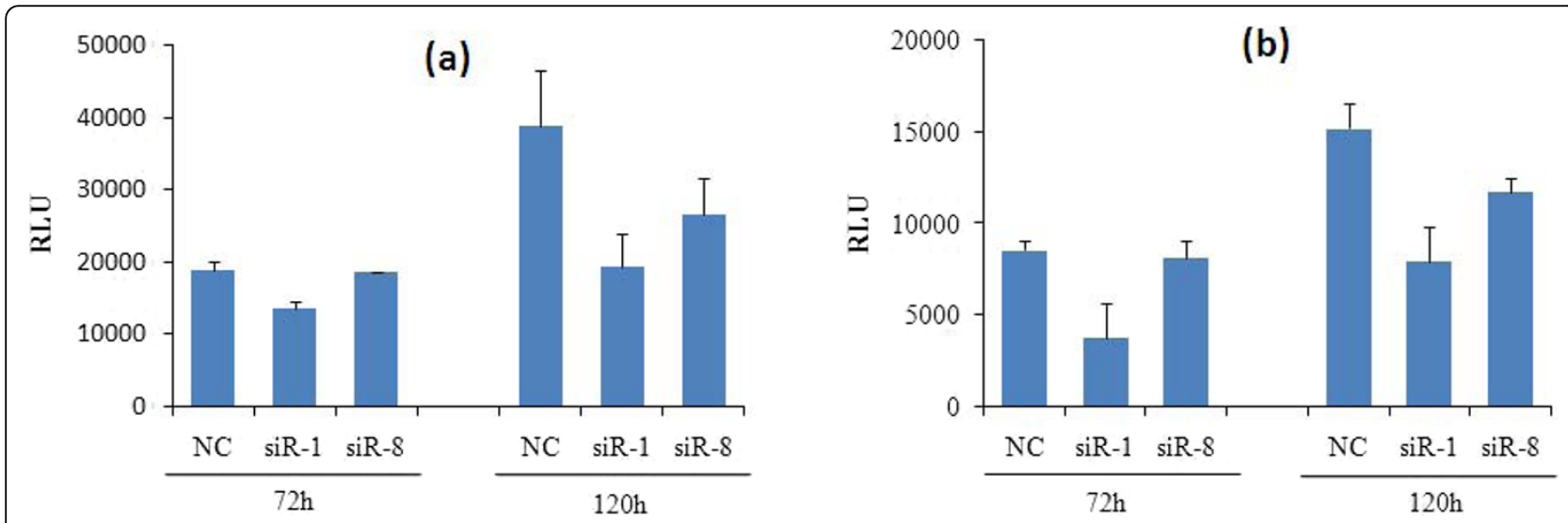

Figure 5 Effect of IKKe siRNA on cell proliferation. (a) SK-BR-3 cells and (b) MCF-7 cells were transfected with siR-1, siR-8, and negative control siRNA (NC). Cell growth was assayed at 72 hours and 120 hours post-transfection using the CellTiter-Glo ${ }^{\oplus}$ Luminescent Cell Viability Assay Kit. Result represented as mean \pm standard deviation $(n=3)$. RLU, Relative Luminescence Unites. 

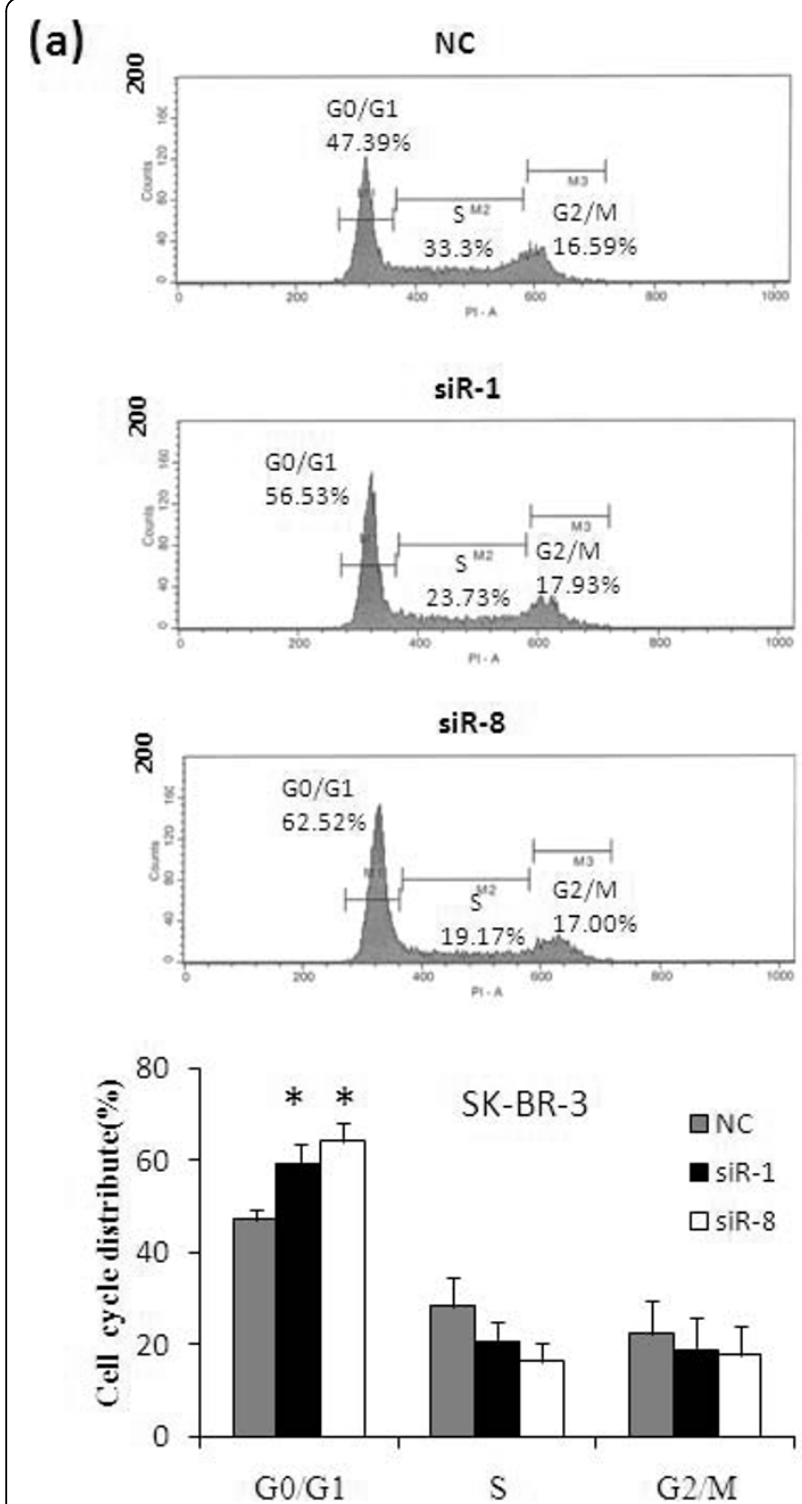

(b)

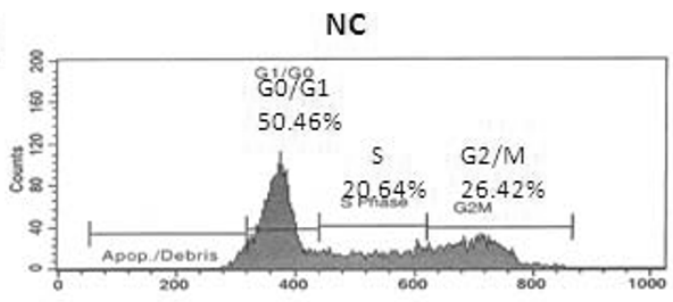

siR-1

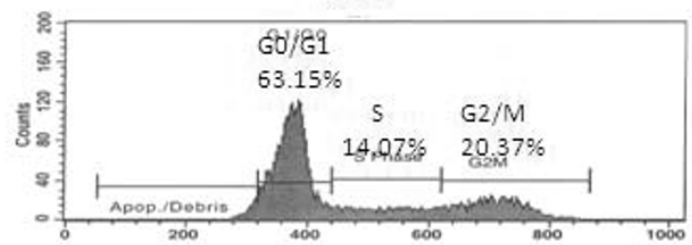

siR-8
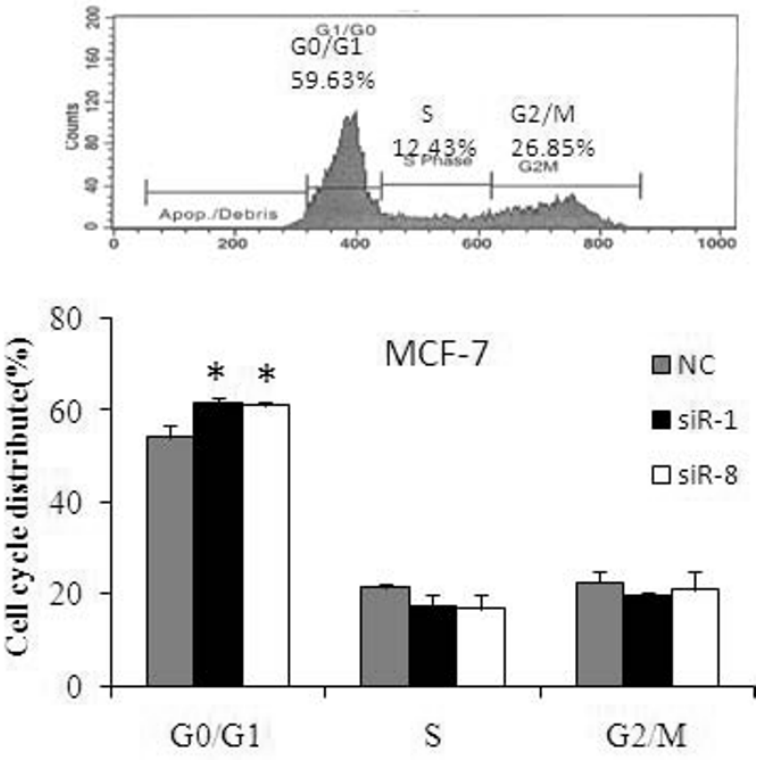

Figure 6 Silencing of IKK $\varepsilon$ leads to $G_{0} / G_{1}$ phase arrest. Cell cycle distribution of (a) SKBR-3 cells and (b) MCF-7 cells treated with 50 nM siR1, siR8, and scrambled siRNA were accessed by flow cytometry 48 hours post-transfection. Results are representative of three independent experiments, represented as mean \pm standard deviation $(n=3)$. NC, negative control siRNA.

\section{Silencing of IKKE induces negligible apoptosis}

Flow cytometry was next used to assay the apoptosis of breast cancer cells after inhibition of IKKe using siRNA. No significant difference of Annexin-V-positive apoptotic cells was observed in the IKK $\varepsilon$ siRNA-treated group in comparison with cells transfected with scrambled siRNA. As Figure 7 indicated, IKK $\varepsilon$-specific siRNA, siR1 and siR-8, induced apoptosis in $4.0 \%$ and $6.4 \%$ of SKBR-3 cells, respectively, while the scrambled siRNA induced apoptosis in $5.9 \%$ of cells $(P=0.821)$. In MCF7 cells, siR-1, siR-8, and scrambled siRNA induced apoptosis in $10.2 \%, 14.7 \%$ and $11.2 \%$ of cells respectively $(P=0.266)$. No significant difference was observed in this study, suggesting that knockdown of IKK $\varepsilon$ alone may not induce apoptosis of breast cancer cells.

\section{Silencing of IKK $\boldsymbol{\varepsilon}$ decreases the basal activity of NF- $\kappa \mathbf{B}$}

To determine whether the knockdown of IKK $\varepsilon$ gene affects the constitutive NF- $\kappa \mathrm{B}$ activity in breast cancer cells, the NF- $\kappa \mathrm{B}$-dependent luciferase reporter assay was performed. Cells were transfected with siRNA for 24 hours, followed by co-transfection with the NF- $\kappa \mathrm{B}$ MetLuc2 reporter vector and the $\beta$-galactosidase reporter vector, which was used as an internal control to normalize the transfection efficiency. As shown in Figure 8 , the NF- $\kappa \mathrm{B}$ transcriptional activity was reduced 


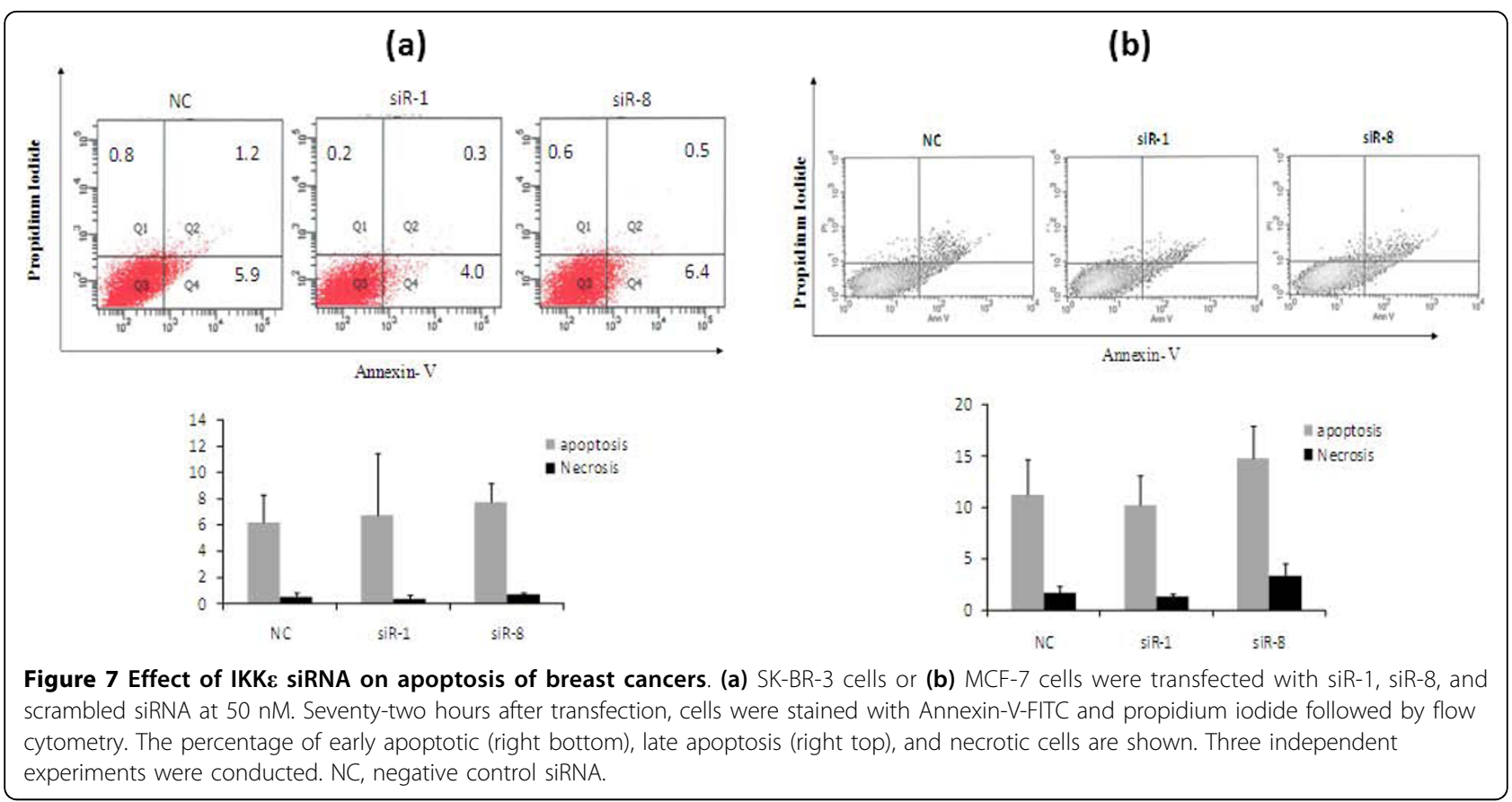

in cells treated with $\mathrm{IKK} \varepsilon$ siRNA in comparison with cells treated with scrambled siRNA. In MCF-7 cells, the NF- $\kappa$ B basal level in IKK $\varepsilon$ siRNA-treated cells decreased to around 42 to $46 \%$ of the control group. Similar result was also observed in SK-BR-3 cells, where the NF- $\kappa$ B basal level decreased to approximately 47 to $58 \%$ of the control group upon IKKe silencing. This result suggests that IKKE may play an important role in controlling the NF- $\kappa \mathrm{B}$ dependent activity in breast cancer cells. This is in agreement with the finding that IKKE activates the NF- $\kappa$ B pathway in breast cancer, although the mechanism is not fully elucidated $[6,11]$.

\section{Silencing of IKKE regulates NF- $\kappa$ B-related downstream genes}

It is reported that breast cancer cells overexpressing IKK $\varepsilon$ showed increased expression of Bcl-2 compared with cells without IKKe overexpression [6]. The Bcl-2 expression levels in SK-BR-3 cells and MCF-7 cells were therefore examined after the inhibition of $I K K \varepsilon$. As indicated in Figure 9a, b, the Bcl-2 mRNA level decreased in both SK-BR-3 cells and MCF-7 cells after the treatment with siR-1 and siR-8. This is in accordance with a previous finding that suppression of the IKK $\varepsilon$ gene resulted in downregulation of Bcl-2 expression [6]. We also examined the protein level of Bcl-2 using western blot (Figure 9c, d). Consistent with the mRNA results, both SK-BR-3 cells and MCF-7 cells showed reduction of Bcl-2 protein expression after the IKK $\varepsilon$ siRNA treatment. Image J software was used to normalize the Bcl-2 expression with $\beta$-actin. In SK-BR-3 cells, the normalized Bcl-2 expressions of siR-1 and siR-8 siRNA treated cells were $40 \%$ and $66 \%$, respectively, in comparison with the control group. In MCF-7 cells, the normalized Bcl-2 expressions of siR-1 and siR- 8 siRNA-treated cells were $88 \%$ and $48 \%$, respectively, in comparison with the control group.

Since cyclin $D_{1}$ was reported as the key regulatory protein for progression through the $G_{1}$ phase of breast cancer cells [20], we next examined whether the expression of cyclin $D_{1}$ was responsible for the $G_{0} / G_{1}$ cell cycle arrest in IKKe siRNA-treated cells. As Figure 9c, d indicates, silencing of IKK $\varepsilon$ significantly decreased the expression of cyclin $\mathrm{D}_{1}$ in breast cancer cells. In SK-BR3 cells, the normalized Bcl-2 expressions of siR-1 and siR-8 siRNA-treated cells were $64 \%$ and $34 \%$, respectively, in comparison with the control group. In MCF-7 cells, the normalized Bcl-2 expressions of siR-1 and siR-8 siRNA-treated cells were $71 \%$ and $45 \%$, respectively, in comparison with the control group. Overexpression of cyclin $D_{1}$ has been shown to shorten the $G_{1}$ phase, and subsequently increase the cell proliferation [21]. This result therefore suggests that cyclin $D_{1}$ is an important mediator in the oncogenic role of IKKE in breast cancer.

Inhibition of $\mathrm{NF}-\kappa \mathrm{B}$ has been reported to sensitize breast cancer cells to doxorubicin [22]. Overexpression of IKK $\varepsilon$ is associated with cell resistance to cisplatin in ovarian cancer. Silencing of IKK $\varepsilon$ sensitized ovarian cancer cells to cisplatin-induced apoptosis and cell death [23]. Moreover, IKKE is an important mediator that protects cells from DNA-damage-induced cell death [24]. 

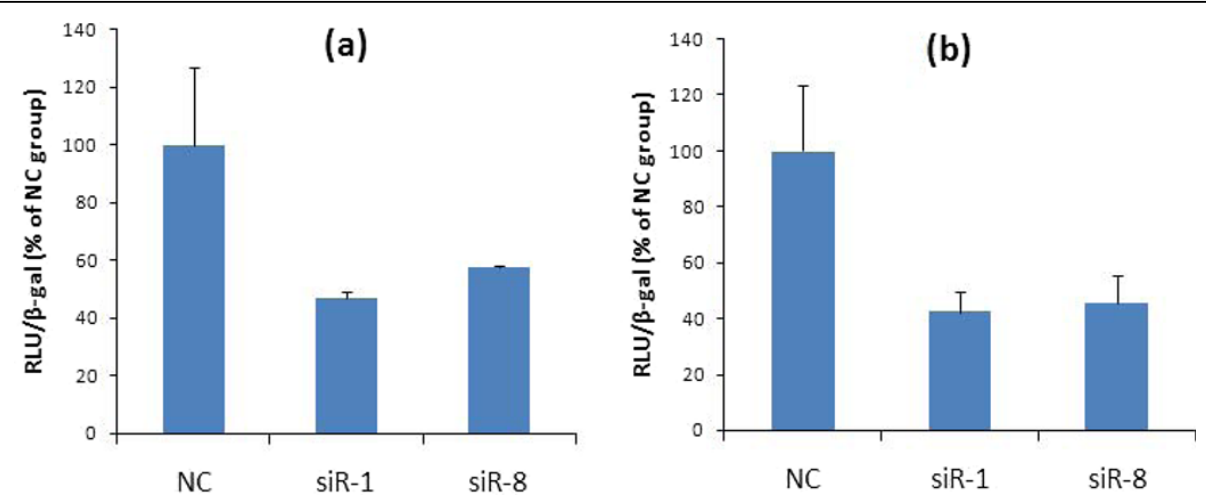

Figure 8 Silencing of IKKE expression reduces basal NF- $\kappa$ B transcriptional activity in SK-BR-3 cells and MCF-7 cells. Twenty-four hours after the siRNA transfection, (a) SK-BR-3 cells and (b) MCF-7 cells were co-transfected with the NF- $\kappa$ B Met Luc2 reporter vector, which contains the NF- $\kappa \mathrm{B}$ promoter element upstream of the luciferase gene, and the $\beta$-galactosidase reporter vector as an internal control. The expression of luciferase was used to monitor the transcriptional activity of NF- $\kappa$ B. The relative luciferase activity was normalized with the $\beta$-galactosidase expression. Result representative of three independent experiments. ${ }^{*} P<0.05$. NC, negative control siRNA; RLU, Relative Luminescence Unites.

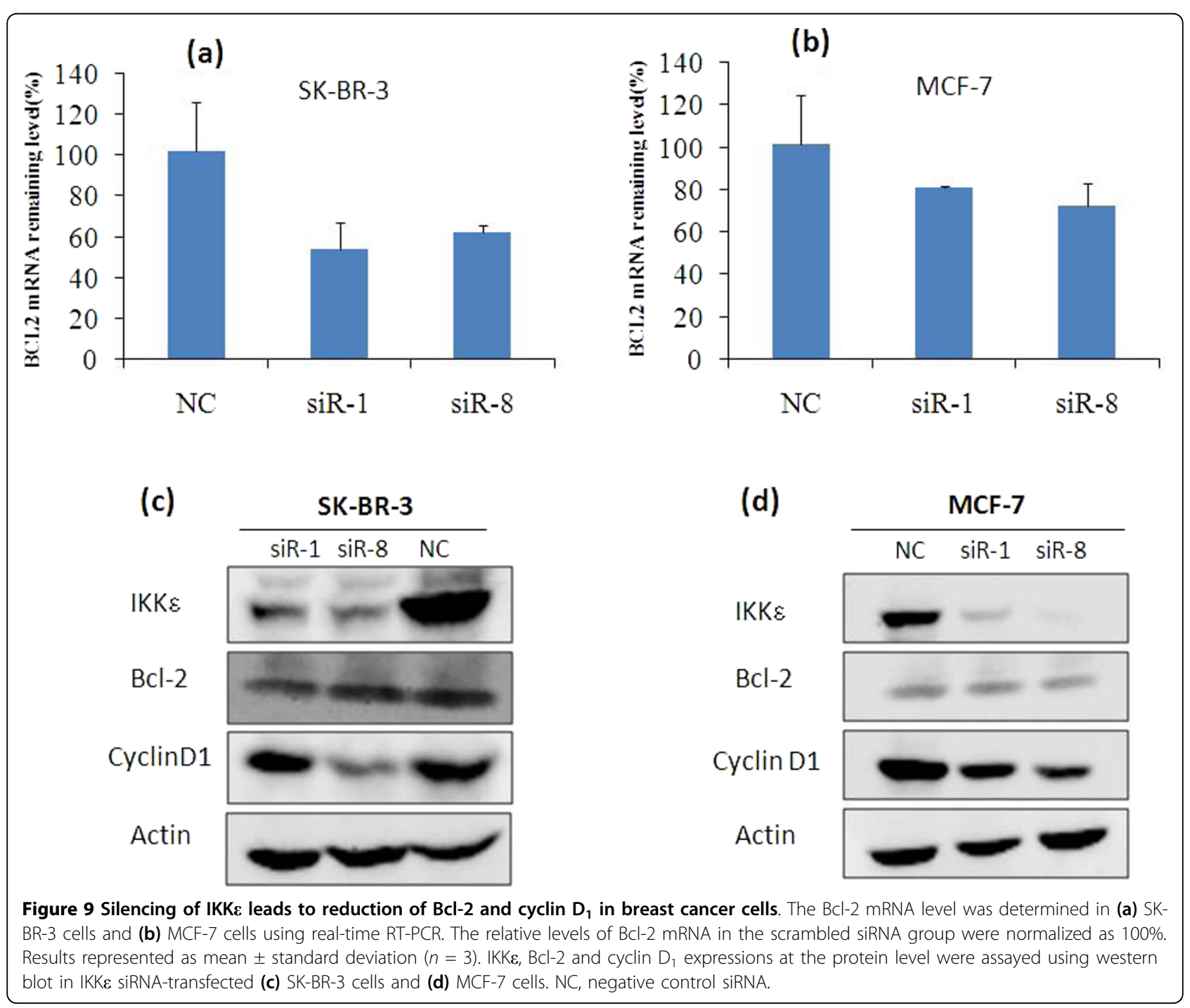


Therefore it would be interesting to evaluate whether IKK $\varepsilon$ silencing can sensitize the response of breast cancer cells to chemotherapy reagents. Herein we investigated the response of breast cancer cells to cisplatin and doxorubicin after silencing IKKe. MCF-7 cells and SKBR-3 cells were transfected with $50 \mathrm{nM}$ IKK $\varepsilon$ siRNA or scrambled siRNA, followed by incubation with different concentrations of cisplatin or doxorubicin. After 24 hours of incubation, cell viability was measured by the MTT assay. As Figure 10 showed, IKKE suppression did not sensitize breast cancer cells to cisplatin (10 to $100 \mu \mathrm{M})$ (Figure 10a, b) and doxorubicin $(0.1$ to $10 \mu \mathrm{M})$ (Figure 10c, d).

\section{Discussion}

The NF- $\kappa$ B pathway plays an important role in immune response, inflammation, and cancer development [25]. As a recently indentified kinase in the NF- $\kappa$ B pathway, $\mathrm{IKK} \varepsilon$ is upregulated in a great proportion of breast cancer cells as well as tumor specimens [6]. Our findings support the hypothesis that IKKe plays an important role in the tumorigenesis of breast cancer.

IKK $\varepsilon$ plays an important role in cell transformation, and activation of the NF- $\kappa$ B pathway is involved in the IKKe-mediated transformation [6]. The tumor suppressor CYLD is directly phosphorylated by IKK $\varepsilon$ at serine418 to decrease its deubiquitinase activity, which is essential to the IKKE-induced transformation [7]. Moreover, breast cancer cells Hs578T stably expressing IKK $\varepsilon$ K38A (kinase-inactive IKKe) showed dramatically low colony formation ability in soft agar compared with cells transfected with the control vector (pCDNA3-FLAGIKKE) [11]. Consistent with these observations, we found that silencing of IKK $\varepsilon$ with siRNA led to significant reduction in focus formation in both MCF-7 cells and SK-BR-3 cells (Figure 2).

Several lines of evidence implicate that NF- $\kappa \mathrm{B}$ and NF- $\kappa$ B-related IKKs are involved in cell invasion and tumor metastasis [26,27]. For example, prevention of IKK $\alpha$ activation resulted in inhibition of prostate cancer

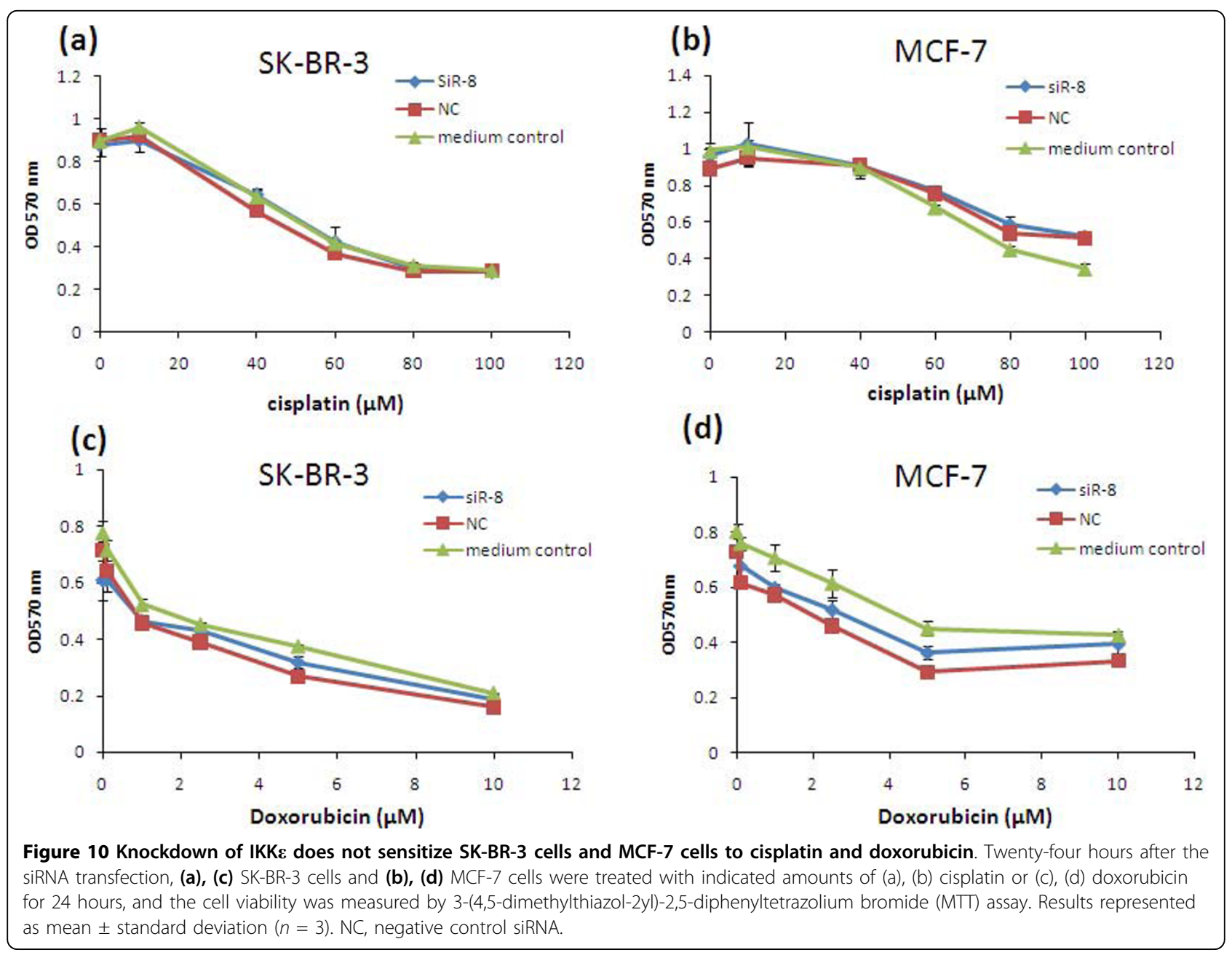


metastasis in TRAMP mice [28]. For the first time, we conducted numerous experiments including the wouldhealing assay, migration assay, and invasion assay to assess the effect of IKK $\varepsilon$ siRNA on invasiveness properties of breast cancer cells. As shown in Figures 3 and 4, the invasiveness properties were significantly inhibited in cells treated with the IKKe siRNA in comparison with cells treated with the scrambled siRNA. These data are consistent with a previous report that breast cancer cells (NF639) transfected with IKKE K38A (kinase-inactive) vectors induced a less invasive phenotype compared with cells transfected with vectors expressing the active IKK $[11]$.

Recent studies have shown that IKKe knockdown with lentiviral shRNA inhibited the proliferation and survival of transformed breast cancer cells, but not the nontransformed human mammary epithelial cells (MCF-10A) [6]. A similar inhibition effect on cell proliferation was also observed in IKKe knockdown Hela cells and ovarian cancer cells $[4,23]$. In agreement with these findings, we observed a significant anti-proliferation effect of IKKE siRNA in breast cancer cells (Figure 5). To further elucidate the mechanism of this anti-proliferation effect, cell cycle analysis was conducted. A significant cell cycle arrest in the $G_{0} / G_{1}$ phase was observed (Figure 6). All these data strongly suggest the role of IKKE in breast cancer proliferation.

We next examined the effect of IKKe on cell apoptosis. There is some controversy regarding the role of IKK $\varepsilon$ in cell apoptosis. It has been reported that IKKe inhibition induces apoptosis in Hela cells [29]. Another report using lentiviral shRNA targeting IKKe, however, did not show any apoptosis in ovarian cancer cells (A2780). Instead, overexpression of IKK $\varepsilon$ was found associated with cisplatin resistance. Significant apoptosis was detected in IKKe knockdown A2780 cells after 20 hours of exposure to cisplatin in comparison with cells treated with cisplatin alone [23]. In the current study, we did not observe significant apoptosis in IKK $\varepsilon$ knockdown SK-BR-3 and MCF-7 cells after silencing IKK $\varepsilon$ using siRNA.

Although the relationship between IKK $\varepsilon$ and NF- $\kappa \mathrm{B}$ is not fully understood, it was postulated that a significant fraction of NF- $\kappa \mathrm{B}$ activation was induced by aberrant IKK $\varepsilon$ expression in tumor cells $[4,6,7]$. Using the NF- $\kappa \mathrm{B}$ transcriptional activity assay, we showed a significant reduction in basal NF- $\kappa$ B activity after IKK $\varepsilon$ suppression (Figure 8). This result is in agreement with a previous finding that IKKe knockdown in Hela cells reduced constitutive activity of the NF- $\kappa \mathrm{B}$ dependent promoter $3 \mathrm{X}-\kappa \mathrm{B}$ [4]. The correlation of IKKe with NF- $\kappa \mathrm{B}$ may explain the role of IKK $\varepsilon$ in malignant transformation and invasiveness of tumor cells.
Moreover, we examined the expression of Bcl-2 and cyclin $\mathrm{D}_{1}$, which are two important proteins regulated by the NF- $\kappa \mathrm{B}$ pathway. $\mathrm{Bcl}-2$ is an important apoptosis regulator involved in processing multiple death signals that are associated with mitochondria [30]. The Bcl-2 expression level correlates with chemotherapy resistance [31-33]. Downregulation of $\mathrm{Bcl}-2$ results in induction of apoptosis and increased sensitivity to chemotherapy drugs $[34,35]$. Knockdown of Bcl-2 in MCF-7 cells using siRNA, however, only increased apoptosis by $9 \%$ (at 72 hours) and $11 \%$ (at 96 hours) in comparison with the control group [36]. In addition, Akar and colleagues demonstrated that cell death (MCF-7 cells) triggered by Bcl-2 siRNA was caused by the induction of autophagic cell death rather than apoptosis. The authors did not observe any apoptosis effect in breast cancer cells upon Bcl-2 silencing [37]. These controversial reports suggested that downregulation of the anti-apoptosis protein Bcl-2 alone does not necessarily result in apoptosis, especially considering the fact that induction of apoptosis is determined by a balance of multiple pro-apoptosis proteins and anti-apoptosis proteins [38]. Similar to these findings, we only observed negligible apoptosis in breast cancer cells (Figure 7), although the Bcl-2 level was downregulated by the IKK $\varepsilon$ siRNA (Figure 9a to 9c). These results might be explained by a compensation of other existed anti-apoptosis factors. In addition, the treatment of IKKE siRNA did not sensitize breast cancer cells to cisplatin and doxorubicin (Figure 10), indicating that silencing IKKe alone may not be sufficient to induce cell apoptosis.

On the other hand, significant inhibition of cyclin $\mathrm{D}_{1}$ was observed in cells treatment with IKK $\varepsilon$ siRNA (Figure $9 d)$. Cyclin $D_{1}$, regulated by the NF- $\kappa B$ pathway, is overexpressed in more than $50 \%$ of breast cancers, and is identified as one of the most commonly upregulated proteins in breast cancer $[39,40]$. There is mounting evidence that cyclin $\mathrm{D}_{1}$ plays a critical role in breast cancer cell cycle control. The induction of cyclin $\mathrm{D}_{1}$ in breast cancer cells shortens the $G_{1}$ phase and increases the number of cells that progress through the $G_{1}$ phase, resulting in an increased proliferation [21]. It was reported that overexpression of an inactive mutant of IKK $\varepsilon$ (K38A) in Hs578T cells resulted in reduction of cyclin $\mathrm{D}_{1}$ [11]. A recent study showed that IKKE phosphorylates estrogen receptor $\alpha$ at serine-167 and subsequently transcriptionally upregulates cyclin $\mathrm{D}_{1}$ [41]. Our results showed that cyclin $\mathrm{D}_{1}$ expressions were downregulated upon IKKE knockdown in both estrogen receptor-positive (MCF-7) and estrogen receptornegative (SK-BR-3) breast cancer cells (Figure 9c, d), and the reduced cyclin $D_{1}$ expressions in both breast cancer cell lines were correlated with a cell cycle arrest in $G_{0} / G_{1}$ (Figure 6a, b). 


\section{Conclusions}

In summary, studies from our laboratory have shown that silencing of IKK $\varepsilon$ with siRNA resulted in significant inhibition of focus formation potential, anchorage-independent growth capability, migration, invasiveness, and proliferation in breast cancer cells. The NF- $\kappa \mathrm{B}$ transcriptional activity and its downstream gene, cyclin $\mathrm{D}_{1}$, were inhibited by IKK $\varepsilon$ siRNAs. The anti-proliferation effect of IKK $\varepsilon$ siRNA is mediated by arresting cells in the $G_{0} / G_{1}$ phase. The present study provided the first evidence that silencing IKK $\varepsilon$ using synthetic siRNA inhibited the invasiveness and proliferation of breast cancer cells. Taken together, our findings not only indicate that IKKe can be a novel therapeutic target for breast cancer treatment, but also suggest a therapeutic potential of targeting IKK $\varepsilon$ with siRNA.

\section{Abbreviations}

BSA: bovine serum albumin; FBS: fetal bovine serum; $\mid \kappa \kappa B$ : inhibitor of $\kappa \kappa \mathrm{B}$; IKK: I KKB kinase; IL: interleukin; MTT: 3-(4,5-dimethylthiazol-2yl)-2,5diphenyltetrazolium bromide; NF: nuclear factor; PBS: phosphate-buffered saline; PCR: polymerase chain reaction; RNAi: RNA interference; RT: reverse transcriptase; shRNA: short hairpin RNA; siRNA: small interfering RNA.

\section{Acknowledgements}

This project has been supported by a Concept Award (W81XWH-08-1-0603) from the Department of Defense Breast Cancer Research Program, and in part by a grant (1R21CA143683-01) from the National Cancer Institute at $\mathrm{NIH}$. The authors also would like to express thanks for the financial support from a start-up package at the University of Missouri-Kansas City.

\section{Authors' contributions}

$\mathrm{KC}$ and $\mathrm{BQ}$ designed the research. $\mathrm{BQ}$ performed the research. $\mathrm{KC}$ and $\mathrm{BQ}$ analyzed the data. $\mathrm{KC}$ and $\mathrm{BQ}$ wrote the paper. All authors read and approved the final manuscript.

\section{Competing interests}

The authors declare that they have a financial competing interest. The authors have submitted a patent disclosure relating to the content of this manuscript.

Received: 12 March 2010 Revised: 9 August 2010

Accepted: 23 September 2010 Published: 23 September 2010

\section{References}

1. Chau TL, Gioia R, Gatot JS, Patrascu F, Carpentier I, Chapelle JP, O'Neill L, Beyaert R, Piette J, Chariot A: Are the IKKs and IKK-related kinases TBK1 and IKK-epsilon similarly activated? Trends Biochem Sci 2008, 33:171-180.

2. Kishore N, Huynh QK, Mathialagan S, Hall T, Rouw S, Creely D, Lange G, Caroll J, Reitz B, Donnelly A, Boddupalli H, Combs RG, Kretzmer K, Tripp CS: IKK-i and TBK- 1 are enzymatically distinct from the homologous enzyme IKK-2: comparative analysis of recombinant human IKK-i, TBK-1, and IKK2. J Biol Chem 2002, 277:13840-13847.

3. Sethi G, Sung B, Aggarwal BB: Nuclear factor-KB activation: from bench to bedside. Exp Biol Med (Maywood) 2008, 233:21-31.

4. Adli $\mathrm{M}$, Baldwin AS: IKK-i//KKE controls constitutive, cancer cell-associated $\mathrm{NF}-\mathrm{kB}$ activity via regulation of Ser-536 p65/RelA phosphorylation. J Biol Chem 2006, 281:26976-26984

5. Peters RT, Liao SM, Maniatis T: IKK is part of a novel PMA-inducible IKB kinase complex. Mol Cell 2000, 5:513-522.

6. Boehm JS, Zhao JJ, Yao J, Kim SY, Firestein R, Dunn IF, Sjostrom SK, Garraway LA, Weremowicz S, Richardson AL, Greulich H, Stewart CJ, Mulvey LA, Shen RR, Ambrogio L, Hirozane-Kishikawa T, Hill DE, Vidal M, Meyerson M, Grenier JK, Hinkle G, Root DE, Roberts TM, Lander ES, Polyak K,
Hahn WC: Integrative genomic approaches identify IKBKE as a breast cancer oncogene. Cell 2007, 129:1065-1079.

7. Hutti JE, Shen RR, Abbott DW, Zhou AY, Sprott KM, Asara JM, Hahn WC, Cantley LC: Phosphorylation of the tumor suppressor CYLD by the breast cancer oncogene IKKe promotes cell transformation. Mol Cell 2009, 34:461-472.

8. Kravchenko W, Mathison JC, Schwamborn K, Mercurio F, Ulevitch RJ: IKKi/ IKK plays a key role in integrating signals induced by pro-inflammatory stimuli. J Biol Chem 2003, 278:26612-26619.

9. Tenoever BR, Ng SL, Chua MA, McWhirter SM, Garcia-Sastre A, Maniatis T: Multiple functions of the IKK-related kinase IKK $\varepsilon$ in interferon-mediated antiviral immunity. Science 2007, 315:1274-1278.

10. Peant B, Diallo JS, Dufour F, Le Page C, Delvoye N, Saad F, Mes-Masson AM: Over-expression of IKB-kinase-epsilon (IKKE/IKKi) induces secretion of inflammatory cytokines in prostate cancer cell lines. Prostate 2009, 69:706-718.

11. Eddy SF, Guo S, Demicco EG, Romieu-Mourez R, Landesman-Bollag E, Seldin DC, Sonenshein GE: Inducible IKB kinase/IKB kinase epsilon expression is induced by $\mathrm{CK} 2$ and promotes aberrant nuclear factor-KB activation in breast cancer cells. Cancer Res 2005, 65:11375-11383.

12. Sithanandam G, Fornwald LW, Fields J, Anderson LM: Inactivation of ErbB3 by siRNA promotes apoptosis and attenuates growth and invasiveness of human lung adenocarcinoma cell line A549. Oncogene 2005, 24:1847-1859.

13. Liu TG, Yin JQ, Shang BY, Min Z, He HW, Jiang JM, Chen F, Zhen YS, Shao RG: Silencing of hdm2 oncogene by siRNA inhibits p53-dependent human breast cancer. Cancer Gene Ther 2004, 11:748-756.

14. Cheng K, Yang N, Mahato RI: TGF-beta1 gene silencing for treating liver fibrosis. Mol Pharm 2009, 6:772-779.

15. Cheng K, Fraga D, Zhang C, Kotb M, Gaber AO, Guntaka RV, Mahato RI: Adenovirus-based vascular endothelial growth factor gene delivery to human pancreatic islets. Gene Ther 2004, 11:1105-1116.

16. TScratch. [http://www.cse-lab.ethz.ch/index.php? \&option=com_content\&view=article\&id $=363]$.

17. Ma L, Teruya-Feldstein J, Weinberg RA: Tumour invasion and metastasis initiated by microRNA-10b in breast cancer. Nature 2007, 449:682-688.

18. Tiang JM, Butcher NJ, Minchin RF: Small molecule inhibition of arylamine $\mathrm{N}$-acetyltransferase type I inhibits proliferation and invasiveness of MDAMB-231 breast cancer cells. Biochem Biophys Res Commun 2010, 393:95-100.

19. Pearson $G$, English JM, White MA, Cobb MH: ERK5 and ERK2 cooperate to regulate NF-KB and cell transformation. J Biol Chem 2001, 276:7927-7931.

20. Imoto $M$, Doki $Y$, Jiang W, Han EK, Weinstein IB: Effects of cyclin $D_{1}$ overexpression on $\mathrm{G}_{1}$ progression-related events. Exp Cell Res 1997, 236:173-180.

21. Musgrove EA, Lee CS, Buckley MF, Sutherland RL: Cyclin $D_{1}$ induction in breast cancer cells shortens $G_{1}$ and is sufficient for cells arrested in $G_{1}$ to complete the cell cycle. Proc Natl Acad Sci USA 1994, 91:8022-8026.

22. Tapia MA, Gonzalez-Navarrete I, Dalmases A, Bosch M, Rodriguez-Fanjul V, Rolfe M, Ross JS, Mezquita J, Mezquita C, Bachs O, Gascon P, Rojo F, Perona R, Rovira A, Albanell J: Inhibition of the canonical IKK/NFkB pathway sensitizes human cancer cells to doxorubicin. Cell Cycle 2007, 6:2284-2292.

23. Guo JP, Shu SK, He L, Lee YC, Kruk PA, Grenman S, Nicosia SV, Mor G Schell MJ, Coppola D, Cheng JQ: Deregulation of IKBKE is associated with tumor progression, poor prognosis, and cisplatin resistance in ovarian cancer. Am J Pathol 2009, 175:324-333.

24. Renner F, Moreno R, Schmitz ML: SUMOylation-dependent localization of IKKE in PML nuclear bodies is essential for protection against DNAdamage-triggered cell death. Mol Cell 2010, 37:503-515.

25. Basseres DS, Baldwin AS: Nuclear factor- $\mathrm{KB}$ and inhibitor of $\mathrm{KB}$ kinase pathways in oncogenic initiation and progression. Oncogene 2006, 25:6817-6830.

26. Sung B, Pandey MK, Nakajima Y, Nishida H, Konishi T, Chaturvedi MM, Aggarwal BB: Identification of a novel blocker of IKBa kinase activation that enhances apoptosis and inhibits proliferation and invasion by suppressing nuclear factor-kB. Mol Cancer Ther 2008, 7:191-201.

27. Lee TK, Poon RT, Wo JY, Ma S, Guan XY, Myers JN, Altevogt P, Yuen AP: Lupeol suppresses cisplatin-induced nuclear factor-KB activation in head and neck squamous cell carcinoma and inhibits local invasion and nodal 
metastasis in an orthotopic nude mouse model. Cancer Res 2007, 67:8800-8809.

28. Luo JL, Tan W, Ricono JM, Korchynskyi O, Zhang M, Gonias SL, Cheresh DA, Karin M: Nuclear cytokine-activated IKKa controls prostate cancer metastasis by repressing Maspin. Nature 2007, 446:690-694.

29. MacKeigan JP, Murphy LO, Blenis J: Sensitized RNAi screen of human kinases and phosphatases identifies new regulators of apoptosis and chemoresistance. Nat Cell Biol 2005, 7:591-600.

30. Desagher S, Martinou JC: Mitochondria as the central control point of apoptosis. Trends Cell Biol 2000, 10:369-377.

31. Ferlini C, Raspaglio G, Mozzetti S, Distefano M, Filippetti F, Martinelli E, Ferrandina G, Gallo D, Ranelletti FO, Scambia G: Bcl-2 down-regulation is a novel mechanism of paclitaxel resistance. Mol Pharmacol 2003, 64:51-58.

32. Tophkhane C, Yang S, Bales W, Archer L, Osunkoya A, Thor AD, Yang X: Bcl2 overexpression sensitizes MCF-7 cells to genistein by multiple mechanisms. Int J Oncol 2007, 31:867-874.

33. Buchholz TA, Garg AK, Chakravarti N, Aggarwal BB, Esteva FJ, Kuerer HM, Singletary SE, Hortobagyi GN, Pusztai L, Cristofanilli M, Sahin AA: The nuclear transcription factor $\mathrm{KB} / \mathrm{bcl}-2$ pathway correlates with pathologic complete response to doxorubicin-based neoadjuvant chemotherapy in human breast cancer. Clin Cancer Res 2005, 11:8398-8402.

34. Emi M, Kim R, Tanabe K, Uchida Y, Toge T: Targeted therapy against Bcl-2related proteins in breast cancer cells. Breast Cancer Res 2005, 7: R940-R952.

35. Julien T, Frankel B, Longo S, Kyle M, Gibson S, Shillitoe E, Ryken T: Antisense-mediated inhibition of the bcl-2 gene induces apoptosis in human malignant glioma. Surg Neurol 2000, 53:360-368, discussion 368369

36. Lima RT, Martins LM, Guimaraes JE, Sambade C, Vasconcelos MH: Specific downregulation of bcl-2 and XIAP by RNAi enhances the effects of chemotherapeutic agents in MCF-7 human breast cancer cells. Cancer Gene Ther 2004, 11:309-316.

37. Akar U, Chaves-Reyez A, Barria M, Tari A, Sanguino A, Kondo Y, Kondo S, Arun B, Lopez-Berestein G, Ozpolat B: Silencing of Bcl-2 expression by small interfering RNA induces autophagic cell death in MCF-7 breast cancer cells. Autophagy 2008, 4:669-679.

38. Hsu SY, Kaipia A, McGee E, Lomeli M, Hsueh AJ: Bok is a pro-apoptotic Bcl2 protein with restricted expression in reproductive tissues and heterodimerizes with selective anti-apoptotic $\mathrm{Bcl}-2$ family members. Proc Natl Acad Sci USA 1997, 94:12401-12406.

39. Gillett C, Fantl V, Smith R, Fisher C, Bartek J, Dickson C, Barnes D, Peters G: Amplification and overexpression of cyclin $D_{1}$ in breast cancer detected by immunohistochemical staining. Cancer Res 1994, 54:1812-1817.

40. Roy PG, Thompson AM: Cyclin $D_{1}$ and breast cancer. Breast 2006 15:718-727.

41. Guo JP, Shu SK, Esposito NN, Coppola D, Koomen JM, Cheng JQ: IKKE phosphorylation of estrogen receptor alpha Ser-167 and contribution to tamoxifen resistance in breast cancer. J Biol Chem 2010, 285:3676-3684.

doi:10.1186/bcr2644

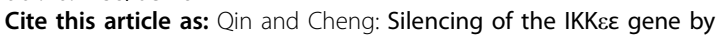
siRNA inhibits invasiveness and growth of breast cancer cells. Breas Cancer Research 2010 12:R74.

\section{Submit your next manuscript to BioMed Central and take full advantage of:}

- Convenient online submission

- Thorough peer review

- No space constraints or color figure charges

- Immediate publication on acceptance

- Inclusion in PubMed, CAS, Scopus and Google Scholar

- Research which is freely available for redistribution

Submit your manuscript at www.biomedcentral.com/submit
Biomed Central 